\title{
Soil phyllosilicate and iron oxide inhibit the quorum sensing of Chromobacterium violaceum
}

\author{
Shanshan Yang ${ }^{1}$, Chenchen $\mathrm{Qu}^{1}$, Manisha Mukherjee ${ }^{2,3}$, Yichao $\mathrm{Wu}^{1}$, Qiaoyun Huang ${ }^{1}$, Peng Cai ${ }^{1, *}$ \\ 1 State Key Laboratory of Agricultural Microbiology, College of Resources and Environment, Huazhong Agricultural University, \\ Wuhan 430070, China \\ 2 Singapore Centre for Environmental Life Sciences Engineering, Nanyang Techological University, Singapore, Singapore 637551 \\ 3 School of Civil and Environmental Engineering, Nanyang Technological University, Singapore, Singapore 639798
}

\section{ARTICLE INFO}

\section{Article history:}

Received March 27, 2020

Revised June 4, 2020

Accepted June 19, 2020

Keywords:

Violacein

Quorum sensing

Signal molecule

Soil mineral

\begin{abstract}
A B S T R A C T
Microorganisms respond to various adverse environmental conditions and regulate different physiological functions by secreting and sensing signal molecules through quorum sensing (QS) systems. Phyllosilicates and iron oxides present in soils and sediments may have substantial impact on bacterial activity and QS due to their unique reactivity and close association with microorganisms. This research explored the effect of goethite, montmorillonite and kaolinite $\left(0.05-2 \mathrm{~g} \mathrm{~L}^{-1}\right)$ on the growth and QS of a bacterial model, Chromobacterium violaceum. The results showed that kaolinite and goethite caused cellular damage at low mineral concentrations. The capacity for violacein production and biofilm formation of $C$. violaceum were inhibited by the minerals in the order of kaolinite > goethite > montmorillonite. The possible underlying mechanisms for QS inhibition by different minerals were investigated. Specifically, kaolinite repressed QS function through downregulation the expression of signal molecules synthesis gene cvil. Goethite and montmorillonite interfered with QS by adsorption of extracellular signal molecules. This work provides a better understanding of the interactions between bacteria and minerals and proposed that the inhibition of QS system is an ignored mechanism for bacterial toxicity by phyllosilicates and iron oxides.
\end{abstract}

C Higher Education Press 2020

\section{Introduction}

The bacterial communities exchange information and modulate their group behavior and functions by secreting and sensing certain signaling molecules, which is termed as quorum sensing (QS) (Fuqua et al., 1994; McClean et al., 1997). The QS system is controlled by the concentration of extracellular signals and participates in sensing and respond-

\footnotetext{
* Corresponding author

E-mail address: cp@mail.hzau.edu.cn (P. Cai)
}

ing to diverse sets of environment, such as nutrient availability, temperature, $\mathrm{pH}$, as well as solid particles (Waters and Bassler, 2005; Masiello et al., 2013). Generally this system regulates various biological processes including biofilm formation, pathogenicity, secondary metabolism, and bioluminescence (Nealson et al., 1970; Greenberg, 1997; Miller and Bassler, 2001). In soils and sediments, bacteria mainly live on the surfaces of different minerals (Steinbach et al., 2015; Whitman et al., 2018), which have cellular toxicity under certain environmental conditions, and may affect the concentration of signal molecules and QS systems (Cai et al., 2013; Xiao et al., 2016; Naik et al., 2018; Qu et al., 2019). 
Thus, exploring how minerals alter microbial activity and QS is an essential prerequisite for thorough understanding of bacteria-mineral interactions.

The clay minerals such as phyllosilicates and iron oxides have strong mobility and high potential to react with organic ligands, which may have profound impacts on bacterial QS through several possible mechanisms. On one hand, minerals may influence the synthesis of signal molecules by inhibiting the survival and growth of bacteria. For example, goethite and kaolinite significantly inhibited the metabolism of Pseudomonas putida, while montmorillonite promoted glucose catabolism (Wu et al., 2014). Some iron oxides and phyllosilicates caused death of bacteria by the reactive oxygen species and aluminum toxicity (Londono et al., 2017; Wang et al., 2017; Ouyang et al., 2018). As a consequence, it is speculated that the cellular density and QS-related enzyme activity may be hindered in the presence of these mineral particles. On the other hand, the minerals can reduce the extracellular concentration of signal molecules by surface adsorption (Masiello et al., 2013; Li et al., 2018). It was reported that the adsorption capacities of signal molecules, acyl-homoserine lactones (AHLs), onto minerals were in the order: montmorillonite $>$ kaolinite $>$ goethite (Liu et al., 2015). Furthermore, in clay-Bordetella sp. composite systems, $1.47 \%$ to $8.20 \%$ of AHLs were adsorbed onto the minerals particles due to electrostatic attraction and hydrogen bonding (Sheng et al., 2017; Sheng et al., 2018). Moreover, the degradation of signal molecules by reactive oxygen species and surface catalytic reactions were observed in $\mathrm{TiO}_{2-}$ Escherichia coli and clay mineral-Vibrio harveyi systems (Xiao et al., 2016; Naik et al., 2018). The response of QS may vary with the reactivity of nanoparticles, thereby producing differential QS signaling profiles (Mohanty et al., 2016). To our knowledge, there is a lack of comparative study of the effect of natural phyllosilicates and iron oxides on QS.

Chromobacterium violaceum is widely distributed in tropical and subtropical regions and is recognized as a human pathogenic bacterium (Shao et al., 2002; Brito et al., 2004; Batista and da Silva Neto, 2017). It regulates violacein release, biofilm formation and other related metabolic processes by releasing and sensing AHLs in the environment (Miller and Bassler, 2001; Liu and Nizet, 2009). The QS system of $C$. violaceum belongs to AHL/Al-1 type, which is common among Gram-negative bacteria (Ruiz et al., 2008). AHL signals are produced constitutively by AHL synthase gene cvil and transported out of the cells. The AHL signals bind to their receptor CviR protein, and the activated AHL-CviR complex finally triggers the transcription of target genes once it reaches the concentration threshold (Miller and Bassler, 2001). The violacein biosynthetic gene cluster vio $A B C D E$ can be triggered by $A H L s / C v i R$ complex in $C$. violaceum. Meanwhile, the protein VioB encoded by vioB was reported to be the rate-limiting step enzyme in violacein production (Balibar and Walsh, 2006; Hoshino, 2011). This bacterium has been used as a model strain for the study of QS under various environmental conditions (Duran et al., 2016; Evans et al., 2018).

We hypothesize that the positively-charged iron oxide inhibits QS by cytotoxicity, and expansive phyllosilicate reduces the concentration of signal molecules by surface adsorption. In this study, iron oxide and two types of natural phyllosilicates, montmorillonite and kaolinite, were chosen to demonstrate their impact on the QS system of $C$. violaceum. The bacterial growth, violacein production, biofilm formation and extracellular signal molecules were monitored in the presence of respective minerals. QS-related genes were determined by quantitative reverse transcription polymerase chain reaction (qRT-PCR). This study may deepen our understanding of bacteria-mineral interactions, and provide insights into the mechanism of QS disturbance raised by natural minerals.

\section{Material and methods}

\subsection{Preparation and characterization of minerals}

Two phyllosilicates microparticles and one iron oxide nanoparticles were used in this study. Kaolinite (KGa-2) and montmorillonite (SWy-2) were purchased from the American Clay Association (http://www.clays.org/sourceclays_data. $\mathrm{html})$. The KGa-2 used in this study is a high defect and low crystallinity kaolinite. The clay-sized fraction of the minerals $(<2 \mu \mathrm{m})$ was isolated based on the procedures described by Rong et al., (2007). Goethite was synthesized by the method of Atkinson et al. (1967). Briefly, $100 \mathrm{~g}$ of $\mathrm{Fe}\left(\mathrm{NO}_{3}\right)_{3} \cdot 9 \mathrm{H}_{2} \mathrm{O}$ was dissolved in $1650 \mathrm{~mL}$ of ultrapure water in a $2 \mathrm{~L}$ beaker. The suspension was vigorously stirred on a magnetic stirrer, and $400 \mathrm{~mL}$ of a $2.5 \mathrm{M} \mathrm{KOH}$ solution was dropped at a rate of $5 \mathrm{~mL} \mathrm{~min}{ }^{-1}$ until the $\mathrm{pH}$ reached 12 . Then the suspension was aged at $60^{\circ} \mathrm{C}$ for $24 \mathrm{~h}$. The precipitate was collected by centrifugation and washed with ultrapure water until the conductivity of the supernatant was less than $20 \mu \mathrm{S} \mathrm{cm}{ }^{-1}$. Mineral suspensions with concentrations of 0.05 to $2 \mathrm{~g} \mathrm{~L}^{-1}$ were prepared in Luria-Bertani (LB) broth. The mineral suspensions were disaggregated using a Sonic Dismembrator (Branson Sonifier 450) for $60 \mathrm{~min}$ at $\sim 160 \mathrm{~W}$ and then autoclaved for $30 \mathrm{~min}$ at $121^{\circ} \mathrm{C}$.

The mineral powders were identified by a Bruker D8 Advance X-ray diffractometer equipped with a LynxEye detector, using Ni-filtered $\mathrm{Cu} \mathrm{Ka}$ radiation. The obtained samples were in good agreement with the diffraction peaks of the standard provided by the international diffraction data center (Fig. S1). Scanning electron microscope (SEM, JSM6390, JEOL, Tokyo, Japan) was used to determine the morphology of the minerals (Fig. S2) (JSM-6390, JEOL, Tokyo, Japan). Before SEM analysis, one drop of the sample suspension was air-dried on an aluminum stub and then coated with $\mathrm{Au}$. The specific surface areas of the minerals were determined in triplicates using a surface area analyzer (ST-08, Beijing, China). Approximately, 100-500 mg samples 
were weighted and measured under $\mathrm{N}_{2} / \mathrm{H}_{2}$ 1:4 mix gas. The total amounts of dissolved $\mathrm{Fe} / \mathrm{Al}$ ions were extracted by mixing $0.1 \mathrm{~g}$ minerals with $5 \mathrm{~mL} 0.1 \mathrm{M} \mathrm{HCl}$ and shaken at $28^{\circ} \mathrm{C}$ for 12 $\mathrm{h}$ and the supernatant liquors were analyzed by inductively coupled plasma optical emission spectrometer (ICP-OES 5110, Agilent). Zeta potential analysis (Zetaplus 90, Brookhaven) was performed with mineral in ultrapure $\mathrm{H}_{2} \mathrm{O}$ at $0.2 \mathrm{~g} \mathrm{~L}^{-1}$ and $\mathrm{pH} 7.0$.

\subsection{Bacterial strain and culture conditions}

The bacterial strain C. violaceum ATCC 12472 was obtained from Fujian Agriculture and Forestry University and stored in glycerol tubes at $-80^{\circ} \mathrm{C}$. Prior to the experiment, the bacteria were first activated in LB medium (10 $\mathrm{g}$ tryptone, $5 \mathrm{~g}$ yeast extract and $10 \mathrm{~g} \mathrm{NaCl}$ in $1 \mathrm{~L}$ deionized water at $\mathrm{pH} 7.0 \pm 0.2$ ), followed by streaking a single colony on LB solid agar plates (LB medium supplemented with $1.5 \%$ agar) and stored at $4^{\circ} \mathrm{C}$. A single colony was picked up and cultured in LB medium at $28^{\circ} \mathrm{C}, 180 \mathrm{rpm}$ for $12 \mathrm{~h}$. Then, $2 \mathrm{~mL}$ of the overnight bacterial suspension was transferred in $200 \mathrm{~mL}$ of LB medium and cultured for another $12 \mathrm{~h}$ under the same condition, until midexponential phase. The bacterial cells were suspended in fresh LB and the optical density at $600 \mathrm{~nm}\left(\mathrm{OD}_{600}\right)$ was adjusted to 0.1 and used immediately.

2.3 Characterization of the growth, morphology, violacein production and biofilm formation of $C$. violaceum in the presence of minerals

A volume of $200 \mu \mathrm{L}$ bacterial suspension $\left(\mathrm{OD}_{600}=0.1\right)$ was incubated with mineral of different concentrations $(0,0.05,0.1$, $0.2,0.5,1,2 \mathrm{~g} \mathrm{~L}^{-1}$ ) in $20 \mathrm{~mL} \mathrm{LB}$ medium at $28^{\circ} \mathrm{C}, 180 \mathrm{rpm}$ for $24 \mathrm{~h}$. Following incubation, the numbers of bacterial cells were estimated by plate dilution technique. The morphology of bacteria-mineral composites were observed using atomic force microscopy (AFM, MultiMode 8, Bruker, Germany) with mineral concentration at $0.2 \mathrm{~g} \mathrm{~L}^{-1}$. Before AFM measurement, $10 \mu \mathrm{L}$ of bacterial suspension was dropped on newly cleaved mica plate and left undisturbed for $5 \mathrm{~min}$, then gently washed thrice with deionized water. The mica sheets were dried at $25^{\circ} \mathrm{C}$ for $2 \mathrm{~h}$ and detected by ScanAsyst-Air probe (nominal elastic constant $0.4 \mathrm{~N} \mathrm{~m}^{-1}$ ) with a NanoScope $\mathrm{V}$ controller at room temperature.

The violacein production by $C$. violaceum was quantified using the flask incubation assay. Three microliters of bacterial suspensions with mineral of different concentrations $(0,0.05$, $0.1,0.2,0.5,1,2 \mathrm{~g} \mathrm{~L}^{-1}$ ) was collected by centrifugation at $15000 \mathrm{~g}$ for $10 \mathrm{~min}$. The bacteria-mineral composites were extracted by dimethyl sulfoxide (DMSO) and centrifuged at $15000 \mathrm{~g}$ for $10 \mathrm{~min}$. The absorbance of the supernatant was measured at wavelength of $585 \mathrm{~nm}$ using a dual beam spectrophotometer (AOE Instruments A580, Shanghai, China). The minerals without bacteria were served as control.

The biofilm formation was measured by crystal violet staining method (Ma et al., 2017). For preparation of the bacteria-mineral complex, $0.5 \mathrm{~mL}$ of bacterial suspension
$\left(O D_{600}=0.1\right)$ was inoculated in $0.5 \mathrm{~mL}$ LB medium amended with $0.4 \mathrm{~g} \mathrm{~L}^{-1}$ minerals in borosilicate glass tubes and cultured at $28^{\circ} \mathrm{C}, 180 \mathrm{rpm}$ for $24 \mathrm{~h}$. Then, the culture suspension was removed and the tube was gently washed twice with $1 \mathrm{~mL}$ of sterile ultrapure $\mathrm{H}_{2} \mathrm{O}$. The biofilm attached to the wall of tubes was stained with $1 \mathrm{~mL}$ of $1 \%(\mathrm{w} / \mathrm{v})$ crystal violet for $15 \mathrm{~min}$, and washed twice with $1 \mathrm{~mL}$ sterile $\mathrm{H}_{2} \mathrm{O}$. The residual crystal violet on biofilm was solubilized in anhydrous ethanol for $30 \mathrm{~min}$ before measuring the absorbance at $540 \mathrm{~nm}$ using a microplate reader (Direai Biological Technology Co. LTD, Wuhan, China).

\subsection{Determination of signal molecules}

The bacteria-mineral complex was prepared by introducing 1 $\mathrm{mL}$ bacterial suspension $\left(\mathrm{OD}_{600}=0.1\right)$ in $100 \mathrm{~mL} \mathrm{LB}$ medium with mineral at $0.2 \mathrm{~g} \mathrm{~L}^{-1}$ and incubated at $28^{\circ} \mathrm{C}, 180 \mathrm{rpm}$ for $24 \mathrm{~h}$. To extract the extracellular signal molecules, the suspension was centrifuged at $15000 \mathrm{~g}$ for $10 \mathrm{~min}$, and the supernatant was passed through a $0.45 \mu \mathrm{m}$ filter, extracted three times with an equal amount of dichloromethane. The dichloromethane extract obtained was rotary-evaporated and dissolved in $5 \mathrm{~mL}$ anhydrous methanol. The solution was mixed with equivalent volume of water before measurement using high performance liquid chromatography-high resolution time-of-flight mass spectrometer (HPLC-MS, Triple TOF 4600, AB company, American). The Agilent C18 column and a flow rate of $0.4 \mathrm{~mL} \mathrm{~min}{ }^{-1}$ were applied to all samples. Solvent A consisted of water and solvent B consisted of methanol, both are HPLC grade with $2 \mathrm{mmol} \mathrm{L}^{-1}$ ammonium acetate and $0.1 \%$ formic acid. A gradient elution method was used as $50 \%$ solvent $B$ for $2 \mathrm{~min}$, followed by gradual increase of solvent B from $60 \%$ to $100 \%$ for $12 \mathrm{~min}$, and maintained $50 \%$ of solvent $\mathrm{B}$ for $19 \mathrm{~min}$. Mass spectrometric analysis was performed under electrospray ionization source (ESI) mode at ion source temperature $120^{\circ} \mathrm{C}$ and desolvation temperature at $350^{\circ} \mathrm{C}$. The $\mathrm{N}_{2}$ was used as desolvation gas and cone gas at flow rate of $500 \mathrm{~L} \mathrm{~h}^{-1}$ and $50 \mathrm{~L} \mathrm{~h}^{-1}$, respectively. The data were collected by information dependent acquisition (IDA) with $50 \mathrm{~ms}$ accumulation time at positive mode. The peak area was calculated by the PeakView software. The following synthetic AHLs (>97\%) purchased from Sigma-Aldrich (Singapore) were used as AHL standards: $N$-hexanoyl-DL-homoserine lactone (C6-HSL), N-octanoyl- $\mathrm{DL}^{-h o m o s e r i n e ~ l a c t o n e ~(C 8-~}$ HSL), N-decanoyl-oL-homoserine lactone (C10-HSL), N-(3oxodecanoyl)-L-homoserine lactone (30C10-HSL).

\subsection{Determination of quorum sensing related gene}

The bacteria-mineral complex was prepared by mixing $3 \mathrm{~mL}$ bacterial suspension $\left(\mathrm{OD}_{600}=0.1\right)$ with $3 \mathrm{~mL} \mathrm{LB}$ medium containing $0.4 \mathrm{~g} \mathrm{~L}^{-1}$ minerals and incubated at $28^{\circ} \mathrm{C}, 180 \mathrm{rpm}$ for $24 \mathrm{~h}$. RNA was extracted using RNeasy Mini Kit following the instructions (Qiagen, Inc. BRD). The concentration and quality of RNA were determined using a Nano Drop 2000 visible spectrophotometer (TS, Inc. USA). Quantitative reverse transcription polymerase chain reaction (qRT-PCR) 
was performed using HiScript $₫$ II Q RT SuperMix (Vazyme, Co., Ltd. CHN). The reaction system contains $5 \mu \mathrm{L} \mathrm{iTaq}^{\text {tm }}$ Universal SYBR green super mix, $1 \mu \mathrm{L}$ upstream primer $\left(2 \mathrm{mmol} \mathrm{L}^{-1}\right), 1 \mu \mathrm{L}$ downstream primer $\left(2 \mathrm{mmol} \mathrm{L}^{-1}\right), 2 \mu \mathrm{L}$ nuclease free water and $1 \mu \mathrm{L}$ cDNA. The reaction was performed at $95^{\circ} \mathrm{C}$ for $5 \mathrm{~min}$, followed by 40 cycles for $10 \mathrm{~s}$ at $95^{\circ} \mathrm{C}$, then $55^{\circ} \mathrm{C}$ for $20 \mathrm{~s}$ and $60^{\circ} \mathrm{C}$ for $35 \mathrm{~s}$. Primers designed to amplify cvil of $C$. violaceum 12472 were 5'-TGGATGTATTTCGTCGTGGA-3'and5'TGAACGGATAAGCTCGGTTT-3' and primers for vio $B$ were 5'-GCTGGTCTACCCGTTCATGT-3' and 5'-GGCCAGGTATTTGAGGAACA-3' (forward and reverse primers, respectively). Gene expression was normalized to the 16S rRNA (forward primer 5'-GCGCAACCCTTGTCCTTAGTT-3'; reverse primer 5'-TGTCACCGGCAGTCTCCTTAG-3').

\subsection{Statistical analysis}

At least three replicates were performed for each experiment. All data were presented as means with standard deviations. One-way analysis of variance (SPSS 18.0 software) was performed based on the experimental data, considering a significant level of $p<0.05$ and highly significant level of $p<0.01$ throughout the study.

\section{Results}

3.1 The growth, biofilm formation and morphology of $C$. violaceum with minerals

Figure 1 shows the biomass of $C$. violaceum in the presence of goethite, montmorillonite and kaolinite at different concentrations. The growth of $C$. violaceum was slightly hampered at low goethite concentrations, and significant inhibition was noticed at goethite concentrations greater than $0.5 \mathrm{~g} \mathrm{~L}^{-1}$ (Fig. 1A). In contrast, the growth was not significantly affected by kaolinite and montmorillonite at the studied mineral concentrations (Fig. 1B and 1C). We further observed the impact of minerals on the biofilm of $C$. violaceum. The minerals inhibited the biofilm formation in varying degrees, and the inhibition was in the order of kaolinite > goethite > montmorillonite (Fig. 2).

The height and peak force error images for $C$. violaceum and their associations with minerals are shown in Fig. 3. C. violaceum has an oval shape with a cell length, width and height of $1.89 \pm 0.52,0.97 \pm 0.11$ and $0.28 \pm 0.01 \mu \mathrm{m}$, respectively. Wrinkles were found to surround the cell periphery, which may be attributed to the thin peptidoglycan layer and bilayer of phospholipids and lipopolysaccharides for Gramnegative bacteria (Huang et al., 2015). Tight associations were observed for kaolinite and goethite on $C$. violaceum surfaces (Fig. 3B and $3 \mathrm{D}$ ), while montmorillonite bind loosely around the cells (Fig. 3C). There were no significant changes in the length and width of bacterial cells in the presence of minerals. However, we observed the height of some cells obviously decreased to less than $0.15 \mu \mathrm{m}$ in the presence of kaolinite and goethite, indicating breakage of cytoplasmic membrane and leakage of cytoplasm (Fig. 3B and 3D). The ratios of the damaged cells in goethite and kaolinite systems were approximately $15 \%(n=27)$ and $30 \%(n=24)$,
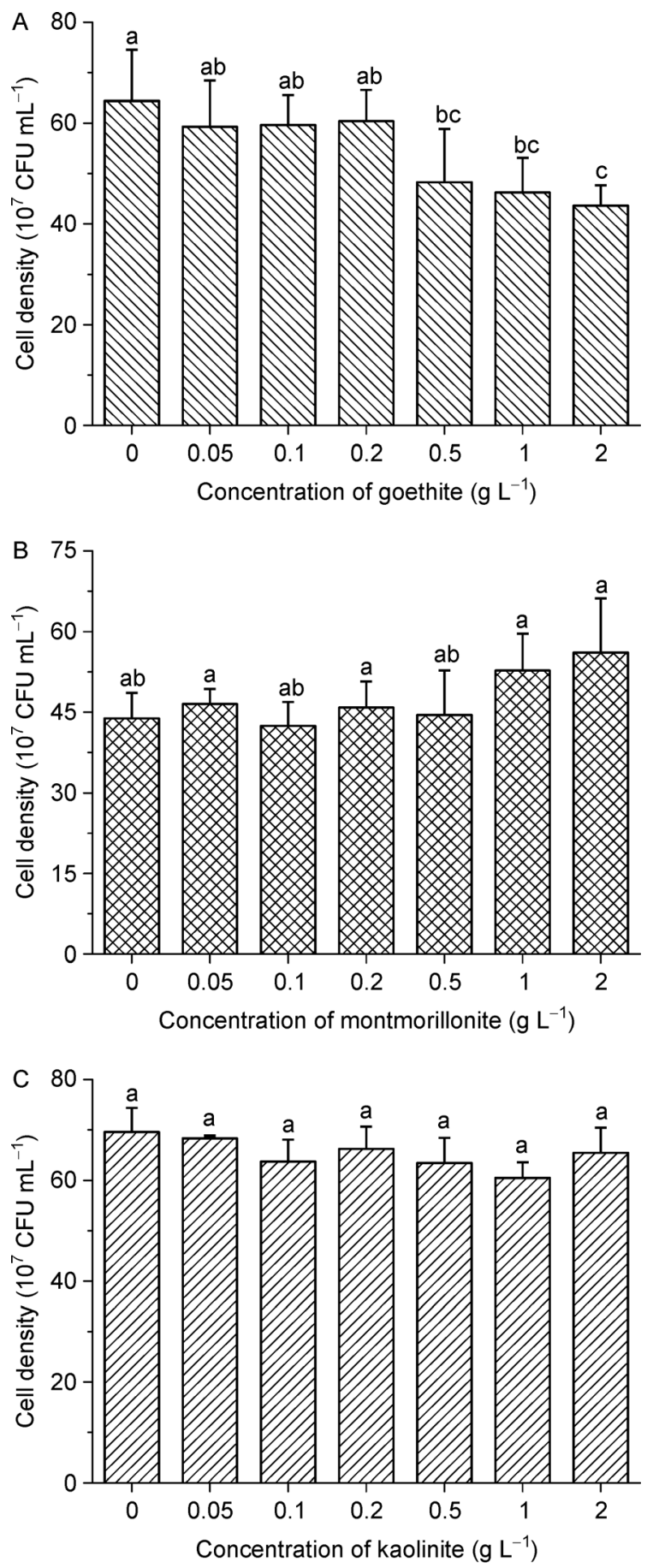

Fig. 1 Cell growth of $C$. violaceum with the impact of goethite $(A)$, montmorillonite $(B)$ and kaolinite $(C)$ under different mineral concentrations $\left(0,0.05,0.1,0.2,0.5,1,2 \mathrm{~g} \mathrm{~L}^{-1}\right)$. All values represent mean $\pm \mathrm{SD}$. Bar with letters are statistically different $(p<0.05)$. 


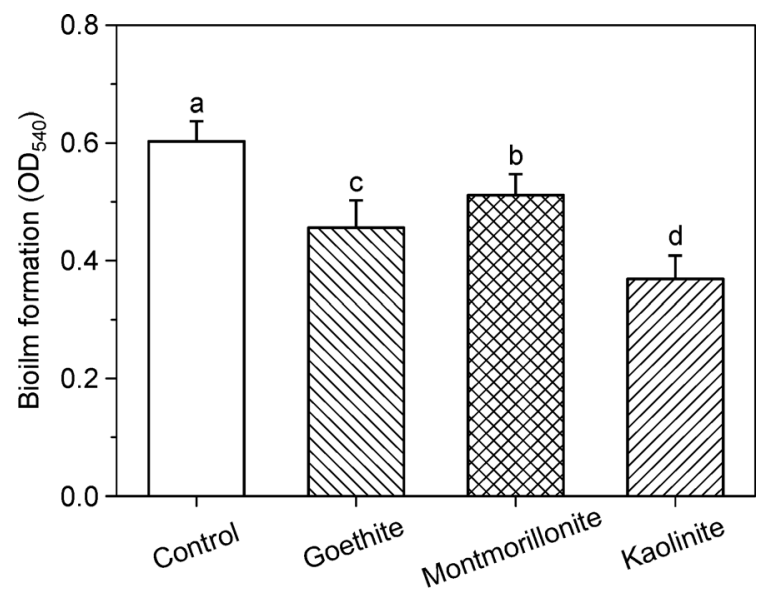

Fig. 2 Impact of goethite, montmorillonite and kaolinite on the biofilm development of $C$. violaceum. All values represent mean $\pm S D$. Bar with letters are statistically different $(p<0.05)$.

respectively. Though kaolinite and goethite did not decrease the biomass of $C$. violaceum at low concentrations, they may trigger cytotoxicity when attached to bacterial surfaces. There was negligible damage for $C$. violaceum when exposed to montmorillonite $(n=21)$.

3.2 Impact of different minerals on the release of violacein from C. violaceum

The amounts of violacein released by $C$. violaceum were affected in the presence of minerals (Fig. 4). All minerals have shown concentration-dependent suppression of violacein production, remarkable inhibitions were observed at high mineral concentrations. Specifically, the influence of mon- tmorillonite was limited and only $8 \%$ reduction of violacein yield was observed at concentration of $0.2 \mathrm{~g} \mathrm{~L}^{-1}$ (Fig. 4B). In contrast, $0.2 \mathrm{~g} \mathrm{~L}^{-1}$ goethite leads to $25 \%$ decrease of violacein production (Fig. 4A). Kaolinite had the most adverse effect on violacein production (Fig. 4C). Intriguingly, decrease in violacein production was observed even at low kaolinite concentrations, a $45 \%$ reduction was detected when the mineral content reached $0.2 \mathrm{~g} \mathrm{~L}^{-1}$. It was worth noting that the capability of kaolinite to inhibit violacein production was comparable to that of the currently developed QS inhibitor $\mathrm{AgCl}-\mathrm{TiO}_{2}$ and fungus tyrosol (Naik and Kowshik, 2014; Chang et al., 2019).

3.3 Changes in the signal molecules in different mineral systems

The concentration of signal molecules in solution is a significant factor for assessing the influence of mineral particles on QS. The specific AHLs and their concentrations were identified using HPLC-MS based on standard curves of four synthetic AHLs as quantitative references. Two signal molecules C10-HSL and C8-HSL in C. violaceum were recognized when compared with the standards. We further demonstrated that the concentration of $\mathrm{AHL}$ was altered in the presence of minerals (Fig. 5). When exposed to montmorillonite, the concentration of C8-HSL was apparently reduced, whereas goethite and kaolinite exhibited a slight impact on the concentration of C8-HSL. In contrast, the levels of C10-HSL signal decreased significantly in the presence of goethite and kaolinite, however, exposure to montmorillonite had no significant impact on C10-HSL (Fig. 5B). In line with a recent study, we extended their finding to natural mineral systems that different signals may respond differently to mineral particles (Mohanty et al., 2016).
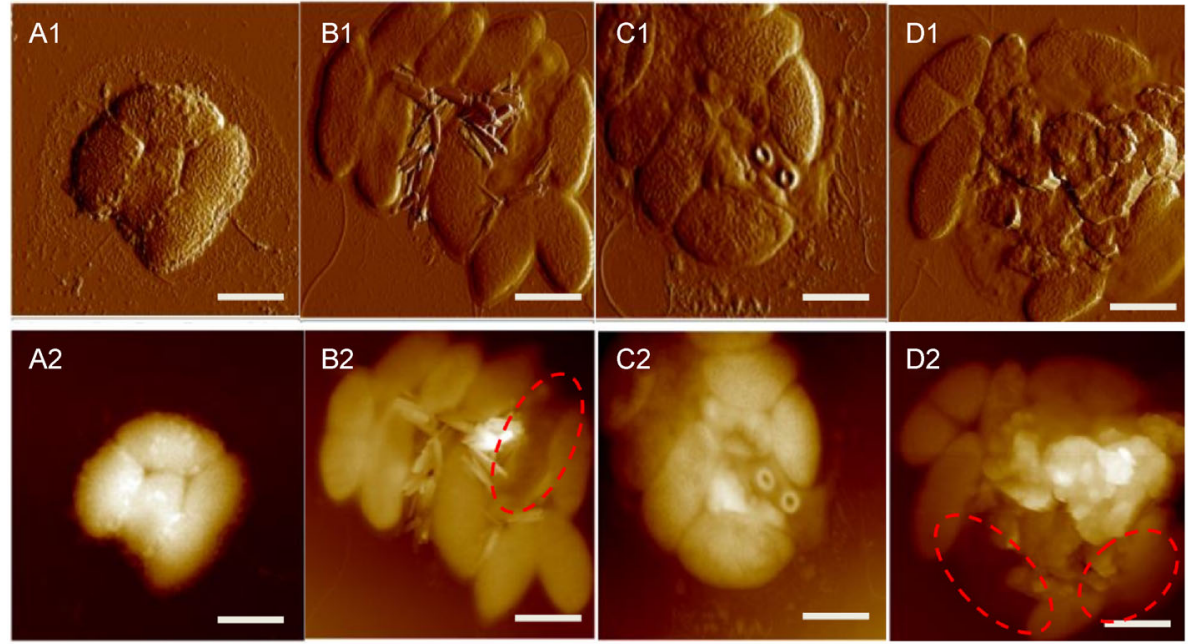

Fig. 3 AFM images of bacteria and their complexes with minerals. Peak force error and height images of C. violaceum (A1, A2), and their association with goethite $(B 1, B 2)$, montmorillonite $(C 1, C 2)$ and kaolinite $(D 1, D 2)$. The red circles show the broken cells. Scale bar $-1 \mu \mathrm{m}$. 

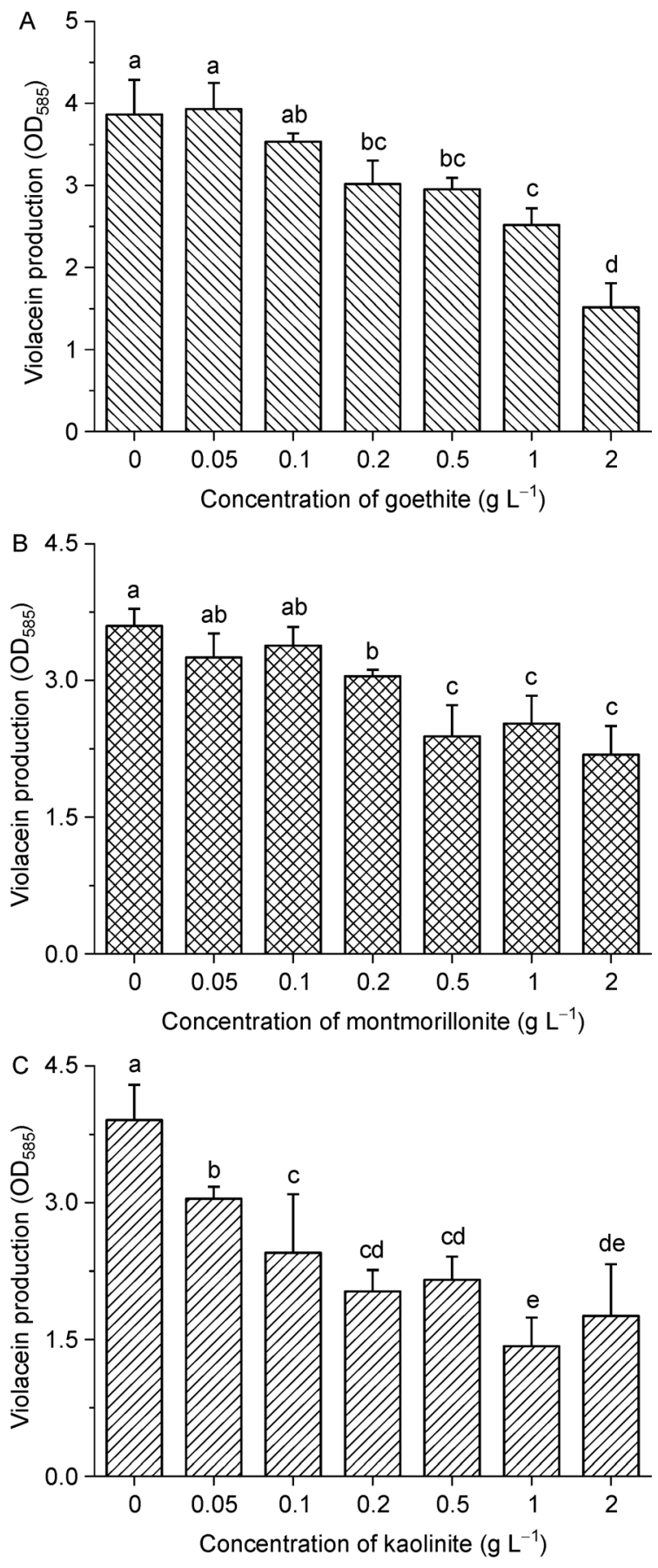

Fig. 4 Violacein production by $C$. violaceum with the impact of goethite $(A)$, montmorillonite $(B)$ and kaolinite $(C)$ under different mineral concentrations $(0,0.05,0.1,0.2,0.5$, $\left.1,2 \mathrm{~g} \mathrm{~L}^{-1}\right)$. Data are presented as mean $\pm \mathrm{SD}$ of absorbance at $585 \mathrm{~nm}$. Bar with letters are statistically different $(p<0.05)$.

3.4 Effects of minerals on quorum sensing related genes of $C$. violaceum

To better understand the response of $C$. violaceum to minerals, genes encoding the synthesis of signal molecules and violacein were quantified by qRT-PCR. It was found that kaolinite downregulated the signal molecule synthesis gene cvil and violacein synthesis gene vioB by $30 \%$ and $80 \%$, respectively (Fig. 6). Goethite and montmorillonite had no influence on cvil gene compared with the control group, but downregulated $v i o B$ gene by $72 \%$ and $52 \%$, respectively. These results indicated that kaolinite may inhibit the synthesis of both signal molecules and violacein. Nevertheless, goethite and montmorillonite did not affect the synthesis of the signal molecules, but inhibited the activity of enzyme VioB.

\section{Discussion}

In this study, goethite, montmorillonite and kaolinite did not suppress the growth of $C$. violaceum at low concentrations. However, the bacterial morphology revealed that the presence of goethite and kaolinite caused damage to bacterial cells. In addition, these minerals also inhibited the violacein production, biofilm formation and QS related gene expression of $C$. violaceum in the order of kaolinite $>$ goethite $>$ montmorillonite, without decreasing the bacterial growth. Schematic of
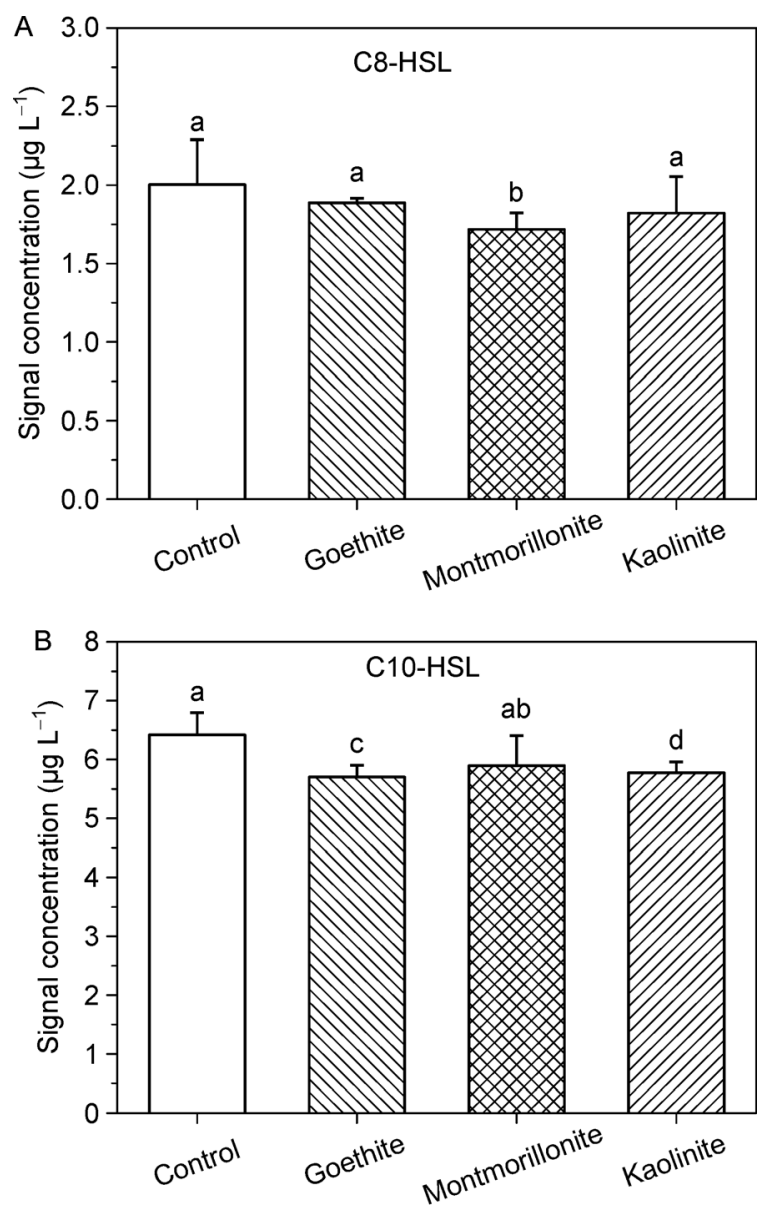

Fig. 5 Influence of minerals $\left(0.2 \mathrm{~g} \mathrm{~L}^{-1}\right)$ on the production of signaling molecule $\mathrm{C} 8-\mathrm{HSL}$ and $\mathrm{C} 10-\mathrm{HSL}$ by $C$. violaceum. All values represent mean \pm SD. Bar with letters are statistically different $(p<0.05)$. 


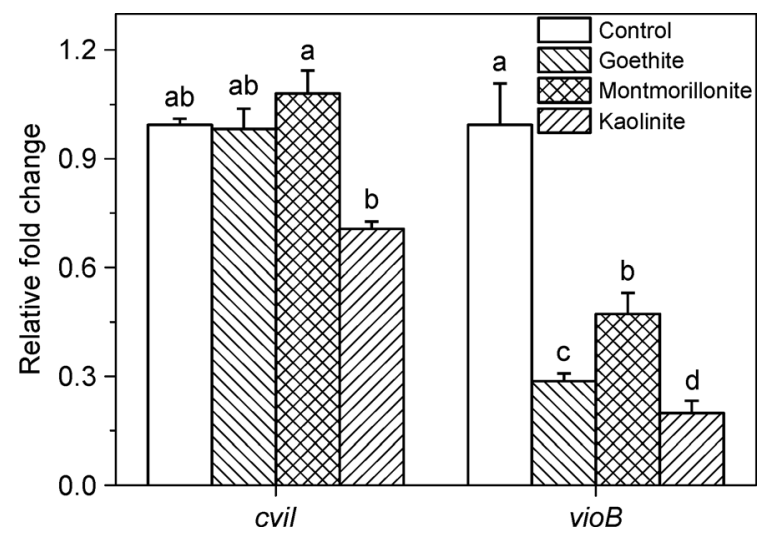

Fig. 6 Expression of $Q S$ related gene cvil and vioB of $C$. violaceum in different mineral systems. All values represent mean \pm SD. Bar with letters are statistically different $(p<0.05)$.

the impact of soil minerals on quorum sensing in C. violaceum is shown in Fig.7. Interestingly, this order is strikingly in line with the metabolism inhibition of $P$. putida by kaolinite, goethite and montmorillonite (Wu et al., 2014). Unexpectedly, kaolinite had the strongest effect on the QS in C. violaceum, even though it exhibited low specific surface area and negative charge (Table 1). The ion analysis found that kaolinite contained high extractable $\mathrm{Al}^{3+}$ ions $\left(242 \pm 15 \mathrm{mg} \mathrm{kg}^{-1}\right.$ ). Meanwhile the aluminum hydroxyl sites on the edge surfaces of kaolinite are positively charged and attractive for bacterial cells (Huang et al., 2015). It is speculated that the $\mathrm{Al}^{3+}$ toxicity and surface adhesion may be the main reason responsible for the toxicity (Londono et al., 2017). Previous studies have demonstrated that iron oxide may cause cytotoxic effects due to their strong electrostatic attraction toward bacterial cells (Cai et al., 2013, Wang et al., 2016; Qu et al., 2019). However, the impact of goethite on the morphology and QS in $C$. violaceum was weaker than that of kaolinite. In the culture medium, the adsorption of organic ligands onto positively charged goethite may reduce their affinity and toxicity to bacteria (Borcherding et al., 2014; Mudunkotuwa and Grassian, 2015). The inhibition of bacterial growth by goethite at high concentrations may be caused by the decrease of nutrient availability for $C$. violaceum. For montmorillonite, the strong negative charge $(-29.5 \mathrm{mV})$ resulted in the weak association with bacteria. Taken together, we conclude that the decrease in bacterial activity inhibited the QS related biofilm formation and the synthesis of violacein in the sequence of kaolinite $>$ goethite $>$ montmorillonite. In addition to bacterial activity, the exposure to mineral particles may interfere with QS through a series of complicated physiological responses. For example, bacteria may increase the mobility to escape physical damage from insoluble minerals by flagellar movement, which also involves the signal transduction (Mohanty et al., 2014; Al-Shabib et al., 2016; Ma et al., 2017). Besides, mineral particles can also induce the production of exopolysaccharide and pilus, and interferes the communication between groups (Cai et al., 2018; Cohen et al., 2019; Li et al., 2019). The impact of soil minerals on these bacterial physiological response and their relations with $Q S$ deserve further investigations.

The reduction of extracellular signal molecule is another way for quenching QS (Fig.7). As expected, the level of extracellular signal C8-HSL was reduced by montmorillonite and the concentration of $\mathrm{C} 10-\mathrm{HSL}$ was reduced by goethite and kaolinite. The decrease can be attributed to the lower AHL synthesis and the adsorption of signal molecule onto mineral surfaces in the medium. A previous study reported that montmorillonite, goethite and kaolinite can adsorb AHLs, and they had the adsorption capacity of 51.94, 26.61 and 21.22 $\mathrm{mg} \mathrm{g}^{-1}$, respectively (Liu et al., 2015). Kaolinite has the lowest adsorption capacity due to its low specific surface area. Our qRT-PCR results showed that kaolinite significantly inhibited the expression of signal molecule synthesis gene, cvil. Therefore, it is proposed that the decrease of AHLs amounts in kaolinite system was due to the decrease in the synthesis of signal molecules. In contrast, the expression of cvil was not

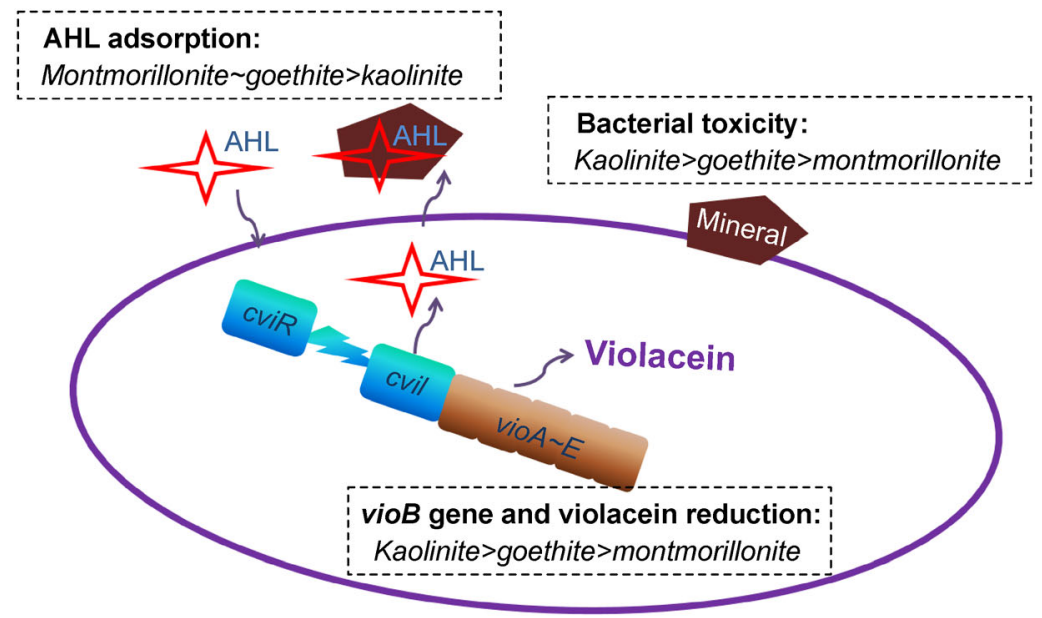

Fig. 7 Schematic of the impact of goethite, montmorillonite and kaolinite on quorum sensing in C. violaceum. 
Table 1 The specific surface area (SSA), Zeta potential and $\mathrm{HCl}$ extractable Fe/Al of minerals.

\begin{tabular}{llccc}
\hline Mineral & SSA $\left(\mathrm{m}^{2} \mathrm{~g}^{-1}\right)$ & Zeta potential $(\mathrm{mV})$ & $\begin{array}{l}\mathrm{Fe}_{\mathrm{HCl}} \\
\left(\mathrm{mg} \mathrm{kg}^{-1}\right)\end{array}$ & $\begin{array}{l}\mathrm{Al}_{\mathrm{HCl}} \\
\left(\mathrm{mg} \mathrm{kg}^{-1}\right)\end{array}$ \\
\hline Goethite & & $34.2 \pm 0.5$ & $384 \pm 12$ & - \\
Montmorillonite & 96.4 & $-29.5 \pm 0.9$ & $382 \pm 14$ & $173 \pm 2$ \\
Kaolinite & 26.1 & $-10.3 \pm 0.3$ & $7.61 \pm 0.35$ & $242 \pm 15$ \\
\hline
\end{tabular}

significantly affected in the presence of goethite and montmorillonite, indicating the synthesis of signal molecules may not be affected. Montmorillonite is an expandable 2:1 type phyllosilicate and the exposed surface area can reach $400 \mathrm{~m}^{2} \mathrm{~g}^{-1}$ in solution (Qu et al., 2018). The specific surface area for goethite is also quite enormous $\left(96.4 \mathrm{~m}^{2} \mathrm{~g}^{-1}\right)$. Considering the concentrations of AHLs were in the range of micrograms per liter in solution, we speculate that the surface adsorption onto minerals resulted in the reduction of extracellular signal molecules in the presence of goethite and montmorillonite. Here, we propose that the adsorption of signal molecules onto mineral surfaces is a universal mechanism for their reduction in the environment. The difference in physicochemical properties including the surface area, charge and adsorption capacity is the main reason behind the differences in QS quenching among the three clay minerals (Masiello et al., 2013; Duran et al., 2016; Li et al., 2018). Several mechanisms including reactive oxygen species, surface adhesion and toxic ions have been proposed for the explanation of mineral toxicity (Londono et al., 2017; Wang et al., 2017). This work provides an alternative explanation that phyllosilicates and iron oxides could quench the common AHL/AI-1 QS system and thus reduce bacterial infection and communication. In natural environments, the mineral particles present in a variety of sizes and generally coexist with organic matters, which tend to remarkably influence the mineralbacteria interactions. Therefore, the size effect of minerals and co-existence of organic matters in the regulation of QS systems of bacterial deserve further investigation. Besides, the influence of mineral particles on bacterial QS signaling may vary among bacterial species, more studies are needed to generalize out findings to other microorganisms

\section{Conclusions}

At low mineral concentrations, the growth of $C$. violaceum was not significantly suppressed in the presence of kaolinite, montmorillonite and goethite. However, all the examined minerals decreased the violacein production by repressing the expression of violacein synthesis gene vioB. The inhibiting effects of soil minerals for bacteria biofilm formation were in the sequence of kaolinite $>$ goethite $>$ montmorillonite. Kaolinite interfered with QS function through downregulatiing the expression of gene related to signal molecule synthesis, cvil. Goethite and montmorillonite hampered QS through the adsorption of the extracellular signal molecules. Cellular toxicity and adsorption of signal molecules are responsible for QS quenching by soil minerals.

\section{Acknowledgments}

This work was supported by the National Natural Science Foundation of China (41877029, 41961130383), Royal SocietyNewton Advanced Fellowship (NAF\R1\191017), the National Key Research Program of China (2016YFD0800206) and Wuhan Science and Technology Bureau (2019020701011469).

\section{Electronic supplementary material}

Supplementary material is available in the online version of this article at https://doi.org/10.1007/s42832-020-0051-5 and is accessible for authorized users.

\section{References}

Al-Shabib, N.A., Husain, F.M., Ahmed, F., Khan, R.A., Ahmad, I., Alsharaeh, E., Khan, M.S., Hussain, A., Rehman, M.T., Yusuf, M., Hassan, I., Khan, J.M., Ashraf, G.M., Alsalme, A., Al-Ajmi, M.F., Tarasov, V.V., Aliev, G., 2016. Biogenic synthesis of zinc oxide nanostructures from Nigella sativa seed: Prospective role as food packaging material inhibiting broad-spectrum quorum sensing and biofilm. Scientific Reports 6, 36761.

Atkinson, R., Posner, A., Quirk, J.P., 1967. Adsorption of potentialdetermining ions at the ferric oxide-aqueous electrolyte interface. Journal of Physical Chemistry 71, 550-558.

Balibar, C.J., Walsh, C.T., 2006. In vitro biosynthesis of violacein from L-tryptophan by the enzymes VioA-E from Chromobacterium violaceum. Biochemistry 45, 15444-15457.

Batista, J.H., da Silva Neto, J.F., 2017. Chromobacterium violaceum pathogenicity: Updates and insights from genome sequencing of novel Chromobacterium species. Frontiers in Microbiology 8, 2213.

Borcherding, J., Baltrusaitis, J., Chen, H., Stebounova, L., Wu, C.M., Rubasinghege, G., Mudunkotuwa, I.A., Caraballo, J.C., Zabner, J., Grassian, V.H., Comellas, A.P., 2014. Iron oxide nanoparticles induce Pseudomonas aeruginosa growth, induce biofilm formation, and inhibit antimicrobial peptide function. Environmental Science. Nano 1, 123-132.

Brito, C.F.A.D., Carvalho, C.B., Santos, F., Gazzinelli, R.T., Teixeira, S. M.R., 2004. Chromobacterium violaceum genome: Molecular mechanisms associated with pathogenicity. Genetics and Molecular Research 3, 148-161.

Cai, P., Huang, Q., Walker, S.L., 2013. Deposition and survival of Escherichia coli $\mathrm{O} 157: \mathrm{H} 7$ on clay minerals in a parallel plate flow system. Environmental Science \& Technology 47, 1896-1903.

Cai, P., Liu, X., Ji, D., Yang, S., Walker, S.L., Wu, Y., Gao, C., Huang, Q., 2018. Impact of soil clay minerals on growth, biofilm formation, 
and virulence gene expression of Escherichia coli 0157:H7. Environmental Pollution 243, 953-960.

Chang, A.P., Sun, S.W., Li, L., Dai, X.Y., Li, H., He, Q.M., Zhu, H., 2019. Tyrosol from marine Fungi, a novel Quorum sensing inhibitor against Chromobacterium violaceum and Pseudomonas aeruginosa. Bioorganic Chemistry 91, 7.

Cohen, N., Zhou, H., Hay, A.G., Radian, A., 2019. Curli production enhances clay- $E$. coli aggregation and sedimentation. Colloids and Surfaces. B, Biointerfaces 182, 182.

Duran, N., Justo, G.Z., Duran, M., Brocchi, M., Cordi, L., Tasic, L., Castro, G.R., Nakazato, G., 2016. Advances in Chromobacterium violaceum and properties of violacein-Its main secondary metabolite: A review. Biotechnology Advances 34, 1030-1045.

Evans, K.C., Benomar, S., Camuy-Velez, L.A., Nasseri, E.B., Wang, X.F., Neuenswander, B., Chandler, J.R., 2018. Quorum-sensing control of antibiotic resistance stabilizes cooperation in Chromobacterium violaceum. ISME Journal 12, 1263-1272.

Fuqua, W.C., Winans, S.C., Greenberg, E.P., 1994. Quorum sensing in bacteria- the LuxR-Luxl family of cell density-responsive transcriptional regulators. Journal of Bacteriology 176, 269-275.

Greenberg, E.P., 1997. Quorum sensing in Gram-negative bacteria. ASM News 63, 371-377.

Hoshino, T., 2011. Violacein and related tryptophan metabolites produced by Chromobacterium violaceum: biosynthetic mechanism and pathway for construction of violacein core. Applied Microbiology and Biotechnology 91, 1463-1475.

Huang, Q., Wu, H., Peng, C., Fein, J.B., Chen, W., 2015. Atomic force microscopy measurements of bacterial adhesion and biofilm formation onto clay-sized particles. Scientific Reports 5, 16857.

Li, G.L., Zhou, C.H., Fiore, S., Yu, W.H., 2019. Interactions between microorganisms and clay minerals: New insights and broader applications. Applied Clay Science 177, 91-113.

Li, N., Wang, L.J., Yan, H.C., Wang, M.Z., Shen, D.S., Yin, J., Shentu, J.L., 2018. Effects of low-level engineered nanoparticles on the quorum sensing of Pseudomonas aeruginosa PAO1. Environmental Science and Pollution Research International 25, 70497058.

Liu, G.Y., Nizet, V., 2009. Color me bad: microbial pigments as virulence factors. Trends in Microbiology 17, 406-413.

Liu, P.L., Chen, X., Chen, W.L., 2015. Adsorption of N-acylhomoserine lactone onto colloidal minerals presents potential challenges for quorum sensing in the soil environment. Geomicrobiology Journal 32, 602-608.

Londono, S.C., Hartnett, H.E., Williams, L.B., 2017. Antibacterial activity of aluminum in clay from the Colombian Amazon. Environmental Science \& Technology 51, 2401-2408.

Ma, W., Peng, D., Walker, S.L., Cao, B., Gao, C.H., Huang, Q., Cai, P., 2017. Bacillus subtilis biofilm development in the presence of soil clay minerals and iron oxides. NPJ Biofilms and Microbiomes 3, 4.

Masiello, C.A., Chen, Y., Gao, X.D., Liu, S., Cheng, H.Y., Bennett, M. R., Rudgers, J.A., Wagner, D.S., Zygourakis, K., Silberg, J.J., 2013. Biochar and microbial signaling: production conditions determine effects on microbial communication. Environmental Science \& Technology 47, 11496-11503.

McClean, K.H., Winson, M.K., Fish, L., Taylor, A., Chhabra, S.R., Camara, M., Daykin, M., Lamb, J.H., Swift, S., Bycroft, B.W.,
Stewart, G., Williams, P., 1997. Quorum sensing and Chromobacterium violaceum: exploitation of violacein production and inhibition for the detection of $\mathrm{N}$-acylhomoserine lactones. Microbiology-Uk 143, 3703-3711.

Miller, M.B., Bassler, B.L., 2001. Quorum sensing in bacteria. Annual Review of Microbiology 55, 165-199.

Mohanty, A., Kathawala, M.H., Zhang, J., Chen, W.N., Loo, J.S.C., Kjelleberg, S., Yang, L., Cao, B., 2014. Biogenic tellurium nanorods as a novel antivirulence agent inhibiting pyoverdine production in Pseudomonas aeruginosa. Biotechnology and Bioengineering 111, 858-865.

Mohanty, A., Tan, C.H., Cao, B., 2016. Impacts of nanomaterials on bacterial quorum sensing: differential effects on different signals. Environmental Science. Nano 3, 351-356.

Mudunkotuwa, I.A., Grassian, V.H., 2015. Biological and environmental media control oxide nanoparticle surface composition: The roles of biological components (proteins and amino acids), inorganic oxyanions and humic acid. Environmental Science. Nano 2, 429-439.

Naik, K., Kowshik, M., 2014. Anti-quorum sensing activity of AgCl$\mathrm{TiO}_{2}$ nanoparticles with potential use as active food packaging material. Journal of Applied Microbiology 117, 972-983.

Naik, S.P., Scholin, J., Ching, S., Chi, F., Herpfer, M., 2018. Quorum sensing disruption in Vibrio harveyi bacteria by clay materials. Journal of Agricultural and Food Chemistry 66, 40-44.

Nealson, K.H., Platt, T., Hastings, J.W., 1970. Cellular control of the synthesis and activity of the bacterial luminescent system. Journal of Bacteriology 104, 313-322.

Ouyang, K., Walker, S.L., Yu, X.Y., Gao, C.H., Huang, Q., Cai, P., 2018. Metabolism, survival, and gene expression of Pseudomonas putida to hematite nanoparticles mediated by surface-bound humic acid. Environmental Science. Nano 5, 682-695.

Qu, C., Du, H., Ma, M., Chen, W., Cai, P., Huang, Q., 2018. Pb sorption on montmorillonite-bacteria composites: A combination study by XAFS, ITC and SCM. Chemosphere 200, 427-436.

Qu, C., Qian, S., Chen, L., Guan, Y., Zheng, L., Liu, S., Chen, W., Cai, P., Huang, Q., 2019. Size-dependent bacterial toxicity of hematite particles. Environmental Science \& Technology 53, 8147-8156.

Rong, X., Huang, Q., Chen, W., 2007. Microcalorimetric investigation on the metabolic activity of Bacillus thuringiensis as influenced by kaolinite, montmorillonite and goethite. Applied Clay Science 38, 97-103.

Ruiz, L. M., S. Valenzuela, M. Castro, A. Gonzalez, M. Frezza, L. Soulère, T. Rohwerder, Y. Queneau, A. Doutheau, and W. Sand. 2008. AHL communication is a widespread phenomenon in biomining bacteria and seems to be involved in mineral-adhesion efficiency. Hydrometallurgy 94:133-137.

Shao, P., Hsueh, P., Chang, Y., Lu, C., Huang, L., 2002. Chromobacterium violaceum infection in children: A case of fatal septicemia with nasopharyngeal abscess and literature review. Pediatric Infectious Disease Journal 21, 707-709.

Sheng, H.J., Harir, M., Boughner, L.A., Jiang, X., Schmitt-Kopplin, P., Schroll, R., Wang, F., 2017. N-acyl-homoserine lactone dynamics during biofilm formation of a 1,2,4-trichlorobenzene mineralizing community on clay. Science of the Total Environment 605, 10311038. 
Sheng, H.J., Wang, F., Gu, C.G., Stedtfeld, R., Bian, Y.R., Liu, G.X. Wu, W., Jiang, X., 2018. Sorption characteristics of $\mathrm{N}$-acyl homserine lactones as signal molecules in natural soils based on the analysis of kinetics and isotherms. RSC Advances 8, 9364 9374.

Steinbach, A., Schulz, S., Giebler, J., Schulz, S., Pronk, G.J., KögelKnabner, I., Harms, H., Wick, L.Y., Schloter, M., 2015. Clay minerals and metal oxides strongly influence the structure of alkane-degrading microbial communities during soil maturation. ISME Journal 9, 1687-1691.

Wang, D., Lin, Z., Wang, T., Yao, Z., Qin, M., Zheng, S., Lu, W., 2016. Where does the toxicity of metal oxide nanoparticles come from: The nanoparticles, the ions, or a combination of both? Journal of Hazardous Materials 308, 328-334.

Wang, X., Dong, H., Zeng, Q., Xia, Q., Zhang, L., Zhou, Z., 2017. Reduced iron-containing clay minerals as antibacterial agents.
Environmental Science \& Technology 51, 7639-7647.

Waters, C.M., Bassler, B.L., 2005. Quorum sensing: Cell-to-cell communication in bacteria. Annual Review of Cell and Developmental Biology 21, 319-346

Whitman, T., Neurath, R., Perera, A., Chu-Jacoby, I., Ning, D.L., Zhou, J.Z., Nico, P., Pett-Ridge, J., Firestone, M., 2018. Microbial community assembly differs across minerals in a rhizosphere microcosm. Environmental Microbiology 20, 4444-4460.

Wu, H., Chen, W., Rong, X., Cai, P., Dai, K., Huang, Q., 2014. Soil colloids and minerals modulate metabolic activity of $P$ seudomonas putida measured using microcalorimetry. Geomicrobiology Journal 31, 590-596.

Xiao, X., Zhu, W.W., Liu, Q.Y., Yuan, H., Li, W.W., Wu, L.J., Li, Q., Yu, H.Q., 2016. Impairment of biofilm formation by $\mathrm{TiO}_{2}$ photocatalysis through quorum quenching. Environmental Science \& Technology 50, 11895-11902. 